\title{
Musashi I modulates cell proliferation genes in the medulloblastoma cell line Daoy
}

\author{
Patricia C Sanchez-Diaz ${ }^{1}$, Tarea L Burton ${ }^{1}$, Suzanne C Burns ${ }^{1}$, \\ Jaclyn Y Hung ${ }^{1,2}$ and Luiz OF Penalva*1,3
}

Address: ${ }^{1}$ Greehey Children's Cancer Research Institute, University of Texas Health Science Center at San Antonio, TX, USA, ${ }^{2}$ Division of Hematology and Oncology, Department of Pediatrics, University of Texas Health Science Center at San Antonio, TX, USA and ${ }^{3}$ Department of Cell and Structural Biology, University of Texas Health Science Center at San Antonio, TX, USA

Email: Patricia C Sanchez-Diaz - sanchezdiaz@uthscsa.edu; Tarea L Burton - burtont@uthscsa.edu; Suzanne C Burns - burnss@uthscsa.edu; Jaclyn Y Hung - hungj@uthscsa.edu; Luiz OF Penalva* - penalva@uthscsa.edu

* Corresponding author

Published: 30 September 2008

BMC Cancer 2008, 8:280 doi:10.1 |86/|47|-2407-8-280
Received: 20 May 2008

Accepted: 30 September 2008

This article is available from: http://www.biomedcentral.com/I47I-2407/8/280

(c) 2008 Sanchez-Diaz et al; licensee BioMed Central Ltd.

This is an Open Access article distributed under the terms of the Creative Commons Attribution License (http://creativecommons.org/licenses/by/2.0), which permits unrestricted use, distribution, and reproduction in any medium, provided the original work is properly cited.

\begin{abstract}
Background: Musashil (Msil) is an RNA binding protein with a central role during nervous system development and stem cell maintenance. High levels of Msil have been reported in several malignancies including brain tumors thereby associating Msil and cancer.
\end{abstract}

Methods: We used the human medulloblastoma cell line Daoy as model system in this study to knock down the expression of Msil and determine the effects upon soft agar growth and neurophere formation. Quantitative RT-PCR was conducted to evaluate the expression of cell proliferation, differentiation and survival genes in Msil depleted Daoy cells.

Results: We observed that MSII expression was elevated in Daoy cells cultured as neurospheres compared to those grown as monolayer. These data indicated that Msil might be involved in regulating proliferation in cancer cells. Here we show that shRNA mediated Msil depletion in Daoy cells notably impaired their ability to form colonies in soft agar and to grow as neurospheres in culture. Moreover, differential expression of a group of Notch, Hedgehog and Wnt pathway related genes including MYCN, FOS, NOTCH2, SMO, CDKNIA, CCND2, CCNDI, and DKKI, was also found in the Msil knockdown, demonstrating that Msil modulated the expression of a subset of cell proliferation, differentiation and survival genes in Daoy.

Conclusion: Our data suggested that Msil may promote cancer cell proliferation and survival as its loss seems to have a detrimental effect in the maintenance of medulloblastoma cancer cells. In this regard, Msil might be a positive regulator of tumor progression and a potential target for therapy.

\section{Background}

Musasi1 (Msi1) is an RNA binding protein essential during nervous system development. It is considered a stem cell marker whose expression has been found to be conserved across species from fly to human [1]. In the mammalian postnatal brain, Msi1 is mainly expressed in cells 
that are believed to be the source of adult neural stem cells [2] and seems to be critical for their maintenance and selfrenewal capability $[1,3,4]$.

High levels of Msi1 have been reported in tumors such as medulloblastoma [5,6], glioma [7,8], astrocytoma [9], retinoblastoma [10] and colorectal adenoma [11]. Indeed, a correlation between high levels of Msi1 expression and poor prognosis has been proposed for glioma and astrocytoma $[8,9]$.

Two Msi1 direct targets have been characterized in mammals: numb [12] and CDKN1A [13]. Binding of Msi1 to specific motifs located in the 3 ' untranslated region (UTR) of these mRNAs seems to interfere with translation, thereby decreasing Numb and p21 WAF (also known as Cdkn1a) protein levels $[12,13]$. Numb is a regulator of three important pathways usually deregulated in cancer: Notch, Hedgehog and p53 (reviewed in [14-17]). Numb represses Notch [18] and Hedgehog [19]. In addition, Numb has recently been shown to prevent degradation of the tumor suppressor p53 [20]. The second known target of Msi1 is the cell cycle inhibitor p21 WAF. Therefore, it is plausible to surmise that by repressing translation of Numb and p21 WAF, high levels of Msi1 might promote aberrant cell proliferation and failure in differentiation and apoptosis.

We observed that the levels of MSI1 were elevated in Daoy neurospheres (high proliferative cultures) compared to monolayers (low proliferative cultures). This data suggested a potential role for Msi1 in promoting cancer cell proliferation in this medulloblastoma cell line. In order to test this hypothesis, we depleted Msi1 in Daoy cells by RNA interference. A significant reduction in soft agar growth (in vitro indicator of tumorigenicity) and neurosphere formation (surrogative measure of "stemness") were observed. We also identified a set of cell proliferation genes whose expression was significantly down-regulated after Msi1 shRNA-mediated knockdown. Thus our data suggested that Msi1 may promote cancer cell proliferation. We propose that Msi1 may maintain a pool of cancer cells with deregulated proliferative capabilities which may possibly serve as a source for future tumorigenic events. In this regard, Msi1 might be a positive regulator of tumor progression and a prospective target for therapeutic intervention.

\section{Methods}

\section{Cell lines, plasmids and transfections}

Daoy cell line was obtained from American Type Culture Collection (ATCC). Cells were cultured in improved minimum essential medium (IMEM) (Invitrogen, Carlsbad, CA, USA) supplemented with $10 \%$ fetal bovine serum (Atlanta Biologicals, Inc., Lawrenceville, GA, USA). Msi1 was knocked down using a shRNAmir retroviral vector targeting the sequence 5'-CGTCCTGTATCATATGTAAAT-3' located in the 3'UTR of Msi1 mRNA (Oligo ID \# V2HS_280120; Open Biosystems). Cells were transfected at 95\% confluency using Lipofectamine2000 reagent (Invitrogen) according to manufacturer's instructions. Stable integration of the plasmid encoding the shRNA was selected using $1 \mu \mathrm{g} / \mathrm{mL}$ of puromycin (InvivoGen, San Diego, CA, USA). A stable Daoy cell line expressing a nonsilencing shRNAmir (Open Biosystems) was also generated as a negative control.

\section{Musashil polyclonal antibody generation}

A 174 nucleotide sequence encoding a 65 aminoacid peptide unique for Msi1 (FPEFRVERTPLPSAPVLPEL TAIPLTAYGPMAAAAAAAAVVRGTGSHPWTMAPPP GSTLERPHRD) was cloned into pGEX-4T-1 (GE Healthcare, Piscataway, NJ, USA) to generate a GSTMsi1 fusion protein. GST-Msi1 recombinant protein was purified to $>90 \%$ homogeneity using Glutathione Sepharose 4B (GE Healthcare) according to manufacturer's instructions. Antibodies raised against Msi1 were affinity-purified from the rabbit antisera by column chromatography in two steps: first using the antigen (GST-Msi1 protein) and then using the GST purified protein. The antibodies were eluted in PBS containing $0.01 \%$ of sodium azide and stored at $-80^{\circ} \mathrm{C}$.

\section{Western blotting}

For western blot analysis cells were disrupted in lysis buffer as described [45]. Equal amounts of protein extract (50 $\mu \mathrm{g}$ per lane) were solubilized in $2 \times$ reducing sample buffer (62.5 mM Tris-Hcl pH 6.8, 25\% glycerol, 2\% SDS, $0.1 \% \mathrm{w} / \mathrm{v}$ Orange G and $40 \mathrm{mM}$ DTT), run on $12 \%$ Trisglycine SDS-Polyacrylamide gels and transferred to nitrocellulose membranes (Invitrogen) using a semi-dry transblot system (Bio-Rad Laboratories, Inc., Hercules, CA, USA). Membranes were stained with $0.1 \% \mathrm{w} / \mathrm{v}$ Ponceau Red (Sigma-Aldrich, St Louis, MO, USA) solution, blocked in $0.1 \%$ Tween 20/PBS containing $5 \%$ w/v nonfat dry milk and incubated over night at $4{ }^{\circ} \mathrm{C}$ with the appropriated antibody; anti- $\beta$ III Tubulin (Abcam, Inc., Cambridge, MA, USA), anti-Bcl-2 (Santa Cruz Biotechnology, Inc., Santa Cruz, CA, USA), anti- $\beta$-Actin (loading control; Abcam) following manufacturers' guidelines, or rabbit anti-Musashi1 polyclonal antibody (described above) at a $0.5 \mu \mathrm{g} / \mathrm{mL}$ final concentration in blocking buffer. After washing in $0.1 \%$ Tween 20/PBS, blots were incubated for 1 hour at room temperature with goat antirabbit IgG HRP conjugated secondary antibody (Santa Cruz) and developed using enhanced chemiluminescence detection (Pierce Biotechnology, Rockford, IL, USA). Experiments were performed twice using different cell extracts. Band densitometry was performed using Adobe 
Photoshop CS3 Extended version 10.0 software (Adobe Systems Incorporated).

\section{Colony formation assay}

The ability of Daoy cells to grow in soft agar was analyzed as described [21]. Briefly, $60 \mathrm{~mm}$ soft agar plates containing 10\% FBS (Atlanta Biologicals) MEM (Invitrogen) and $0.4 \%$ agar noble (BD Biosciences, San Jose, CA, USA) were inoculated with a suspension of $3 \times 10^{3}$ cells of either control or Msi1 knockdown Daoy. Cells were fed once a week by adding $0.5 \mathrm{ml}$ of complete IMEM medium (Invitrogen). After 8 weeks of incubation, colonies were stained over night with $1 \mathrm{mg} / \mathrm{mL} p$-iodonitrotetrazolium solution (Sigma) and scored using the colony counting application from the Quantity One software (Bio-Rad). Three individual clones were tested with each sample analyzed in quadruplicate. Two independent experiments were performed with similar results.

\section{Neurosphere culture assay}

Daoy neurosphere culture was performed as described [46] Briefly, cells were trypsinized and washed in Neurobasal medium (Invitrogen) and resuspended at $5 \times 10^{4}$ cells $/ \mathrm{mL}$ in the same medium containing $2 \mathrm{mM} \mathrm{L}$ glutamine, N2 supplement, B27 supplement, $20 \mathrm{ng} / \mathrm{mL}$ hrEGF, $20 \mathrm{ng} / \mathrm{mL}$ hrbFGF and $50 \mu \mathrm{g} / \mathrm{mL}$ BSA (Invitrogen). $1 \mu \mathrm{g} / \mathrm{mL}$ of puromycin (InvivoGen) was included to ensure shRNA plasmid selection. Fresh growth factors were added to the cells twice a week. Neurospheres were disaggregated in single-cell suspensions and reseeded at clonal density as described [46] to form secondary, tertiary and quaternary spheres. For the neurosphere dilution assay single-cell suspensions of control and Msi1 knockdown Daoy cells were plated in Neurobasal medium in 96-well plates (serial dilutions from 1000 to 1 cell/well). After 10 days incubation the number of spheres larger than $50 \mu \mathrm{m}$ in diameter were quantified in 8 wells. Two independent experiments were performed with similar results.

\section{Quantitative RT-PCR}

RNA was prepared using Trizol reagent (Invitrogen), treated with RNase-free DNaseI (Roche Diagnostics, Indianapolis, IN, USA) as per manufacturer's protocols and tested by PCR to ensure the absence of genomic DNA contamination. Gene specific primers for real-time RT-PCR, listed in Additional file 1, were designed using Primer3 [47] and purchased from Integrated DNA Technologies (IDT, Coralville, IA, USA). One-step RT-PCR reactions were performed using an ABI 7500 real time PCR system (Applied Biosystems, Foster City, CA, USA) following manufacturer's instructions. Briefly, 50 ng total RNA was reverse transcribed at $48^{\circ} \mathrm{C}$ for $45 \mathrm{~min}$ using $150 \mathrm{nM}$ gene specific primers, $0.5 \mathrm{U} / \mu \mathrm{L}$ of MultiScribe Reverse Transcriptase and $0.4 \mathrm{U} / \mu \mathrm{L}$ of RNase Inhibitor in $1 \times$ SYBR
Green PCR Power Master Mix (ABI). RT enzyme was heat inactivated at $95^{\circ} \mathrm{C}$ for $10 \mathrm{~min}$ and PCR was carried out as follows: One cycle of $95^{\circ} \mathrm{C}$ for 5 min and 40 cycles of 15 s at $95^{\circ} \mathrm{C}$ followed by $1 \mathrm{~min}$ at $50-60^{\circ} \mathrm{C}$ according to primers' $\mathrm{Tm}$. Relative gene expression was determined using the comparative $\mathrm{C}_{\mathrm{T}}$ method and the $\mathrm{ABI} 7500$ Prism Software. 15S RNA levels were used as endogenous control for normalization. Specificity of PCR amplification was confirmed by the dissociation curves of the amplicons. Samples were analyzed in quadruplicate using two different RNA preparations.

\section{Hedgehog pathway blockade}

Cyclopamine and its analog tomatidine were purchased from Calbiochem (San Diego, CA, USA) and stocked as 5 $\mathrm{mM}$ solution in $95 \%$ ethanol. Both drugs were used at a concentration range of 5-20 $\mu \mathrm{M}$ in Neurobasal medium prepared as described above. Briefly, neurospheres were dissociated as described [46] and single-cell suspensions reseeded at clonal density in 12-well plates $(10,000$ cells/ well). The effects of Hedgehog blockade upon sphere formation in Daoy control and knockdown cells were evaluated after 7 days of incubation. Two experiments were performed with similar results.

\section{Statistical analysis}

Statistical analysis was performed using GraphPad (GraphPad Software, Inc., San Diego, CA, USA). Data from quantitative RT-PCR, soft agar growth and SP is presented as means \pm standard error (se), and were analyzed by two-tailed unpaired Student's t-test. Differences were considered significant when P-value was below 0.05.

\section{Results \\ Msil expression in Daoy neurosphere cultures}

To determine if Msi1 might play a role in Daoy cancer cell proliferation, we measured the levels of MSI1 mRNA in Daoy neurosphere cultures by quantitative RT-PCR (Figure 1). On average, a 2-fold increase in MSI1 level was detected in neurospheres (actively proliferating culture) compared to monolayers (less actively proliferating culture). Since neurosphere cultures can be enriched in tumor re-initiating cells and Msi1 is a stem cell marker with a role in cell cycle progression [13], the higher level of Msi1 detected in neurospheres indicated that Msi1 may contribute to Daoy cancer cell proliferation.

\section{Generation of a Msil knockdown in the medulloblastoma cell line Daoy}

We depleted Msi1 in the medulloblastoma cell line Daoy using a vector-based siRNA which targeted a sequence unique for Msi1 located in the 3'UTR of the gene. As a negative control, cells were transfected with the same vector containing a non silencing shRNA (Open Biosystems, Inc., Huntsville AL, USA). Three individual clones exhib- 


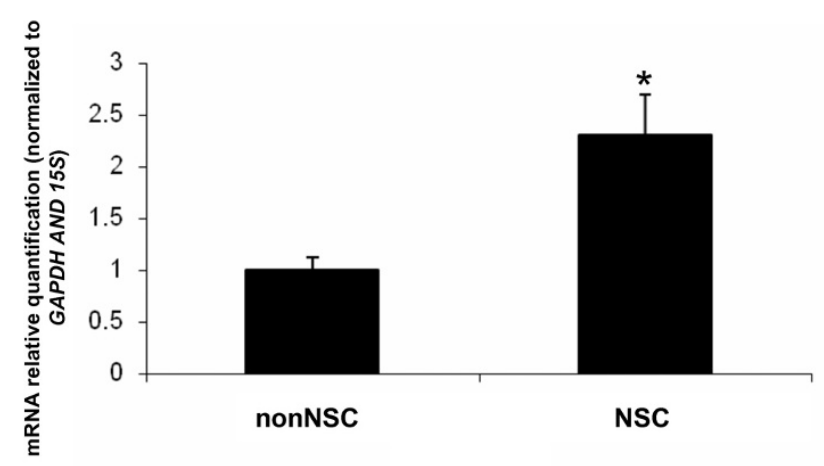

Figure I

Msi I expression in Daoy neurospheres. The levels of MSII RNA levels were analyzed in Daoy cells grown as monolayer (nonNSC) and as neurosphere (NSC) cultures using quantitative RT-PCR. GAPDH and I5S mRNA levels were used as endogenous control for normalization. On average, a 2-fold increase in MSII was detected in the neurosphere cultures. $*$ indicate $\mathrm{p}<0.01$.

iting at least a 70\% knockdown efficiency at the mRNA level (determined by quantitative RT-PCR; Additional file 1) were selected. Msi1 protein knockdown was confirmed by western blot (Additional file 1) using a polyclonal antibody generated in our laboratory.

Msi I knockdown impaired anchorage-independent growth in Daoy cell line

We analyzed the effect of Msi1 on anchorage-independent growth (clonogenicity) in Daoy cells as an in vitro assay for tumorigenicity. Colony formation assays were performed in soft agar as previously described [21]. As shown in Figure 2, Msi1 knockdown reduced the ability of Daoy cells to form colonies in soft agar by 3 to 4 -fold thus indicating that Msi1 promoted cell proliferation in these cancer cells and, consequently, that might play a role in tumor growth.

\section{Msi I sustained cancer cells}

Msi1 is a stem cell marker reported to be essential for maintenance of stem cells [1,3,4]. Cells with stem-like properties have been isolated in many human brain cancers including medulloblastoma (reviewed in [22]). Since high levels of Msi1 are frequently found in medulloblastoma and since we observed that Msi1 expression was elevated in Daoy neurosphere compared to monolayer cultures (Figure 1), we asked if Msi1 might be involved in regulating proliferation in cancer cells. Here we evaluated neurosphere formation as an indicator of cell proliferative potential. Single-cell suspensions were plated at clonal density to minimize the effects of cell aggregation in favor of single-cell sphere generation. After 10 days of incuba- tion, neurospheres larger than $50 \mu \mathrm{m}$ in diameter were counted. As shown in Figure 3, a significant reduction in both number and overall size of the spheres was detected when Msi1 expression was depleted. The defect observed in sphere formation was more severe in subsequent serial passages (data not shown), thus indicating a role for Msi1 in sustaining cancer cells.

\section{Msi I regulates expression of Notch, Hedgehog and Wnt components}

Msi1 represses translation of NUMB [12], which antagonizes the activity of Notch and Hedgehog [18,19]. Recently, it has been shown that Msi1 also activates Notch and Wnt in mammary progenitors through an autocrine mechanism involving up-regulation of Proliferin-1 and down-regulation of Dickkopf-3 [23]. Notch, Hedgehog and Wnt pathways are central regulators of cell proliferation and their deregulation is frequently associated with medulloblastoma (reviewed in [22]). With the high levels of Msi1 reported for medulloblastoma, a connection among Msi1, Notch, Hedgehog and Wnt activities and tumor growth is likely. To investigate if Msi1 was modulating the activity of these pathways in Daoy, the expression of some Notch, Hedgehog and Wnt pathway components and downstream targets were evaluated by quantitative RT-PCR. The primers used for this analysis are listed in Additional file 1. In the knockdown, up-regulation of the Wnt inhibitor Dickkopf-1 (DKK $1 ;>70 \%$ increase) was observed along with a down-regulation in the Wnt downstream target FOS (60\% reduction) as shown in Figure 4. Down-regulation of a subset of Notch and Hedgehog related genes was also found. In this regard, lower levels of the Hedgehog component SMO (50\% decrease) and of the downstream targets $M Y C N$ (90\% decrease), CCND2, PPAP2B and CDKN1A (50\% decrease) were detected in the Msi1 knockdown cells together with lower levels of the relevant Notch component NOTCH2 (40\% decrease) and of the downstream target HEY2 (60\% decrease). Intriguingly, up-regulation of the Wnt and Hedgehog common downstream target CCND1 (>60\% increase) was observed. Overall it seemed that Msi1 modulates expression of a number of genes involved in cell proliferation, differentiation and survival processes. Therefore, our observation was in agreement with Wang et al recent findings using mammary progenitors [23].

\section{Msi I knockdown potentiated the effects of Hedgehog blockade}

To determine the relevance of Hedgehog in cell proliferation in our model system, we performed a neurosphere assay in the presence of different concentrations of cyclopamine. Cyclopamine is a plant alkaloid which antagonizes Smoothened (Smo), a major signal transducer of the Hedgehog pathway [24]. As a negative con- 


\section{2.a}

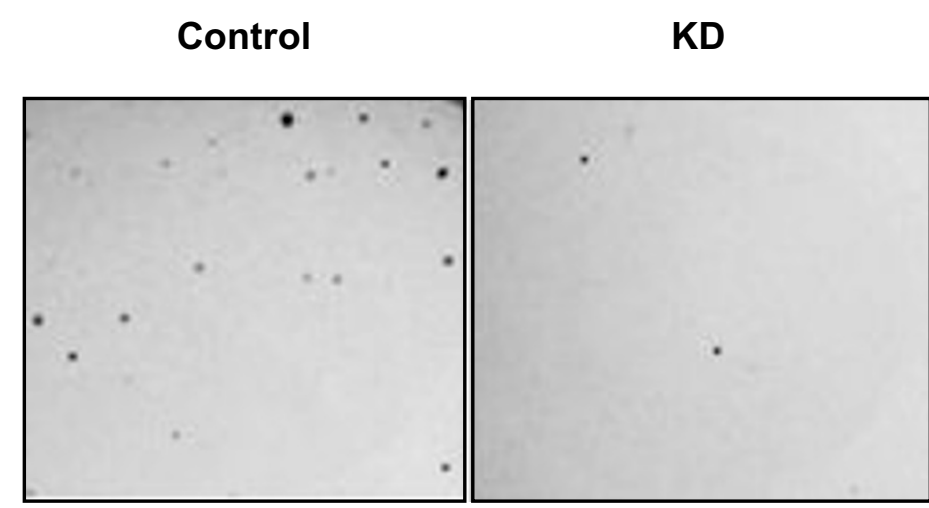

\section{2.b Soft agar assay}

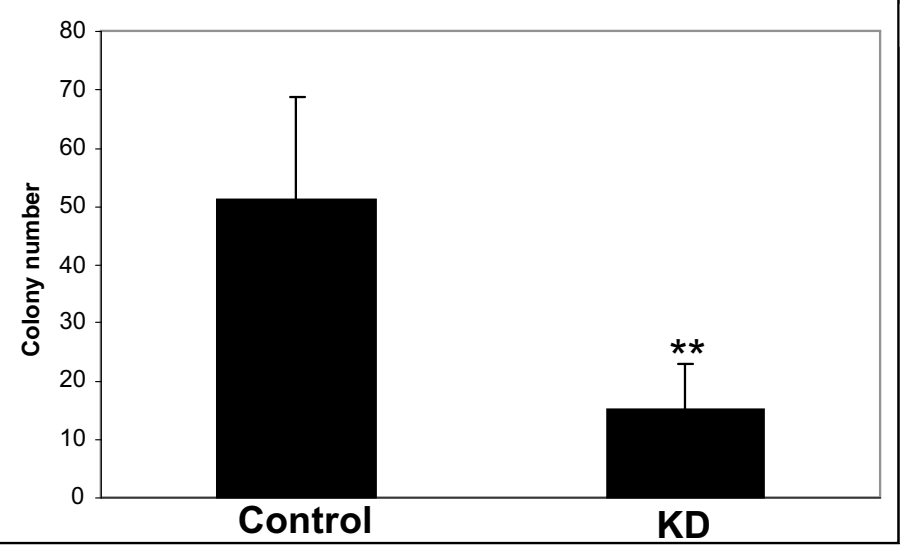

\section{2.c KD\#1}
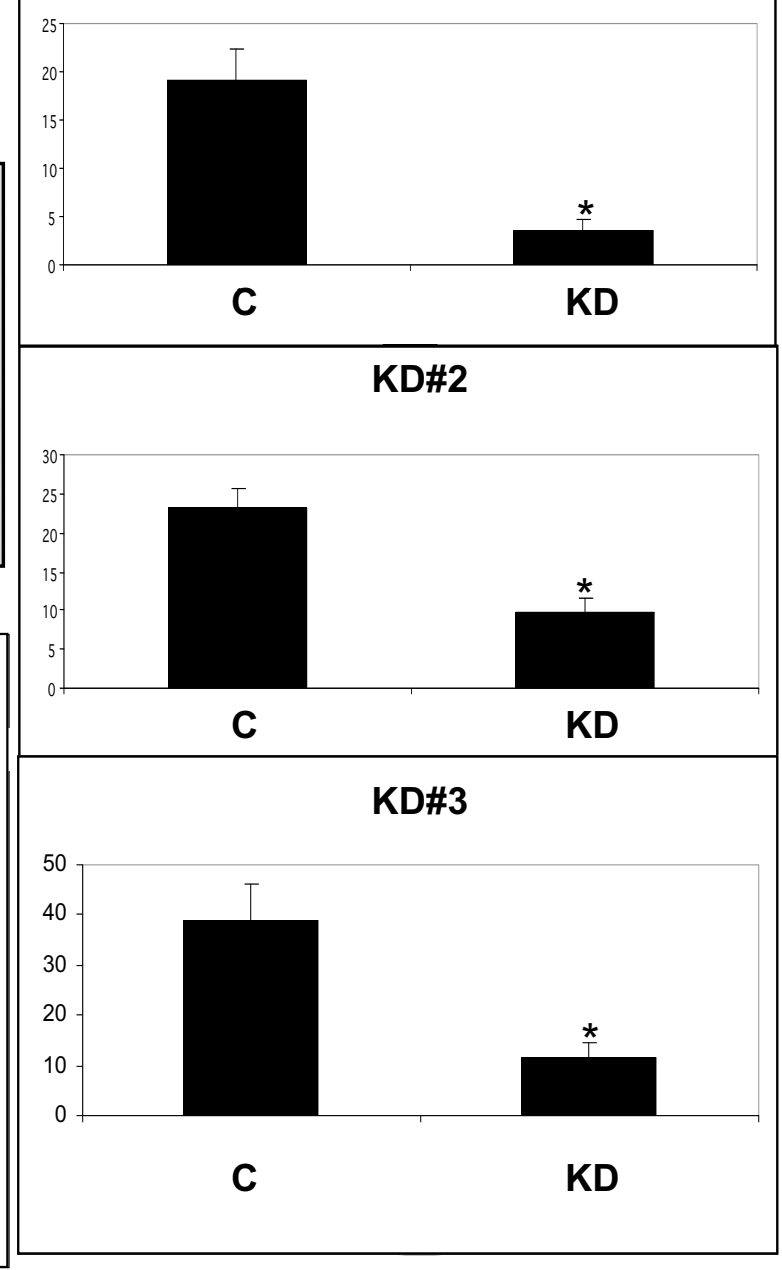

Figure 2

Anchorage-independent growth. The effect of Msil expression upon anchorage-independent growth was studied as an in vitro indicator of tumorigenicity in Daoy cells. Two independent experiments were performed with similar results. Msil depletion reduced the ability to form colonies in soft agar by 3 to 4 -fold which indicated that Msil may sustain the malignant potential of this tumor cell line. a) A representative image of the colonies formed by the control and knockdown (KD) cell lines is shown. The average results for the three clones (b) and for each individual one (c) are represented. * and $* *$ indicate $\mathrm{p}<10^{-3}$ and $\mathrm{p}<10^{-5}$, respectively, compared to control.

trol, we used the structural analog tomatidine at the same concentrations. While $5 \mu \mathrm{M}$ cyclopamine induced a marked reduction in neurosphere size in the Msi1 knockdown cells ( $\mathrm{p}<0.05), 4$ times higher concentrations were needed to elicit a significant effect in the control Daoy cells ( $p<0.01$; Figure 5). Therefore, Hedgehog seems to be important for neurosphere formation in Daoy cells, and the increased susceptibility to cyclopamine observed for Msi1 KD cells may reflect a partial down-regulation in the activity of this pathway.

\section{Msil potential implication in cell differentiation and apoptosis}

In order to determine Msi1's possible involvement in cell differentiation and apoptosis we analyzed the levels of the neural marker $\beta$ III Tubulin and the antiapoptotic protein $\mathrm{Bcl} 2$ by western blot in the cell line Daoy (Figure 6). On average, a 5-fold increase $(\mathrm{p}<0.05)$ in $\beta$ III Tubulin and a 8 -fold decrease $(\mathrm{p}<0.05)$ in Bcl-2 were detected when Msi1 was knocked down. The higher levels of $\beta$ III Tubulin detected in the knockdown indicated that Msi1 arrests cell 
3.a
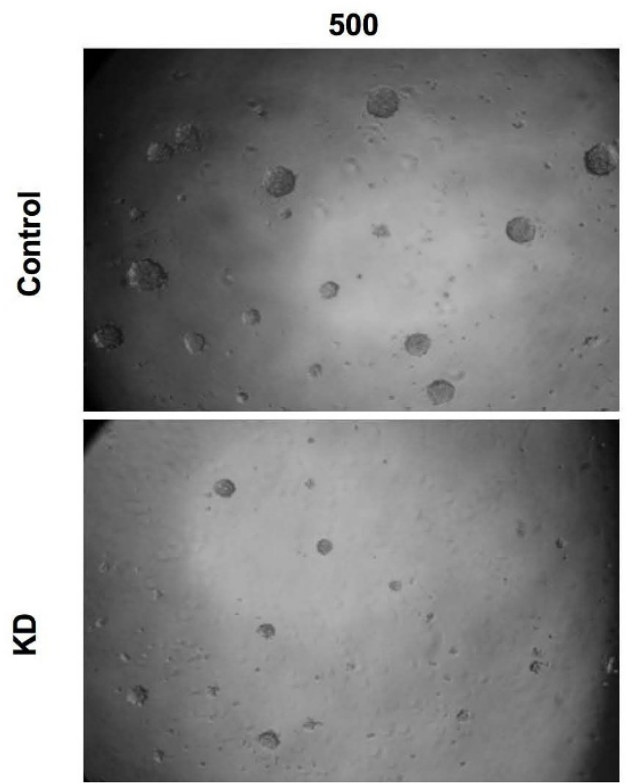

3.b

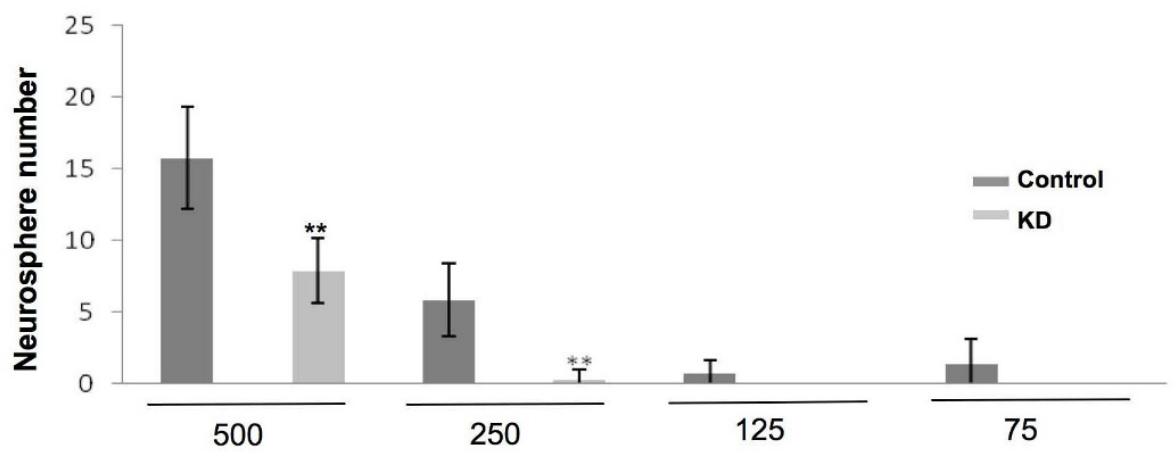

3.c

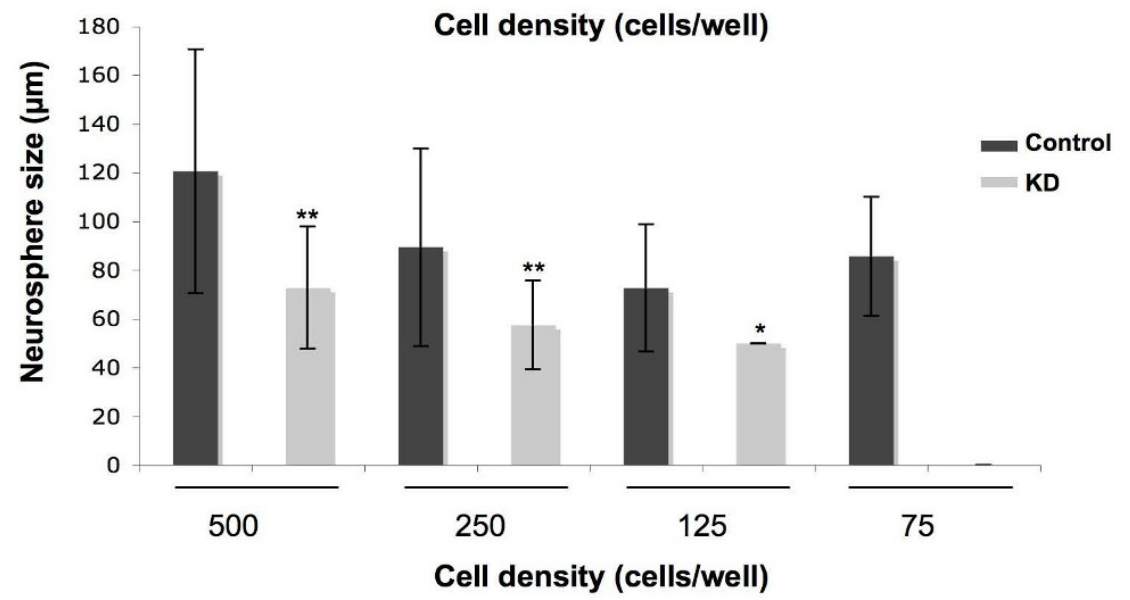

Figure 3

Neurosphere formation assay. a) Second generation of neurospheres derived from Daoy control (upper) and knockdown (KD; lower) at two different cell densities (500 and 250 cells/well) are shown. The smaller size neurospheres detected in the knockdown suggested that Msil controls cell proliferation in Daoy. b) The average number of spheres per well is represented at different cell densities (500, 250, I 25 and 75 cells/well). Only spheres larger than $50 \mu \mathrm{m}$ in diameter were scored. c) The differences in neurosphere size are represented at different cell densities $(500,250,125$ and 75 cells/well). * indicates $p<0.05$ and $* * p<0.0001$. 


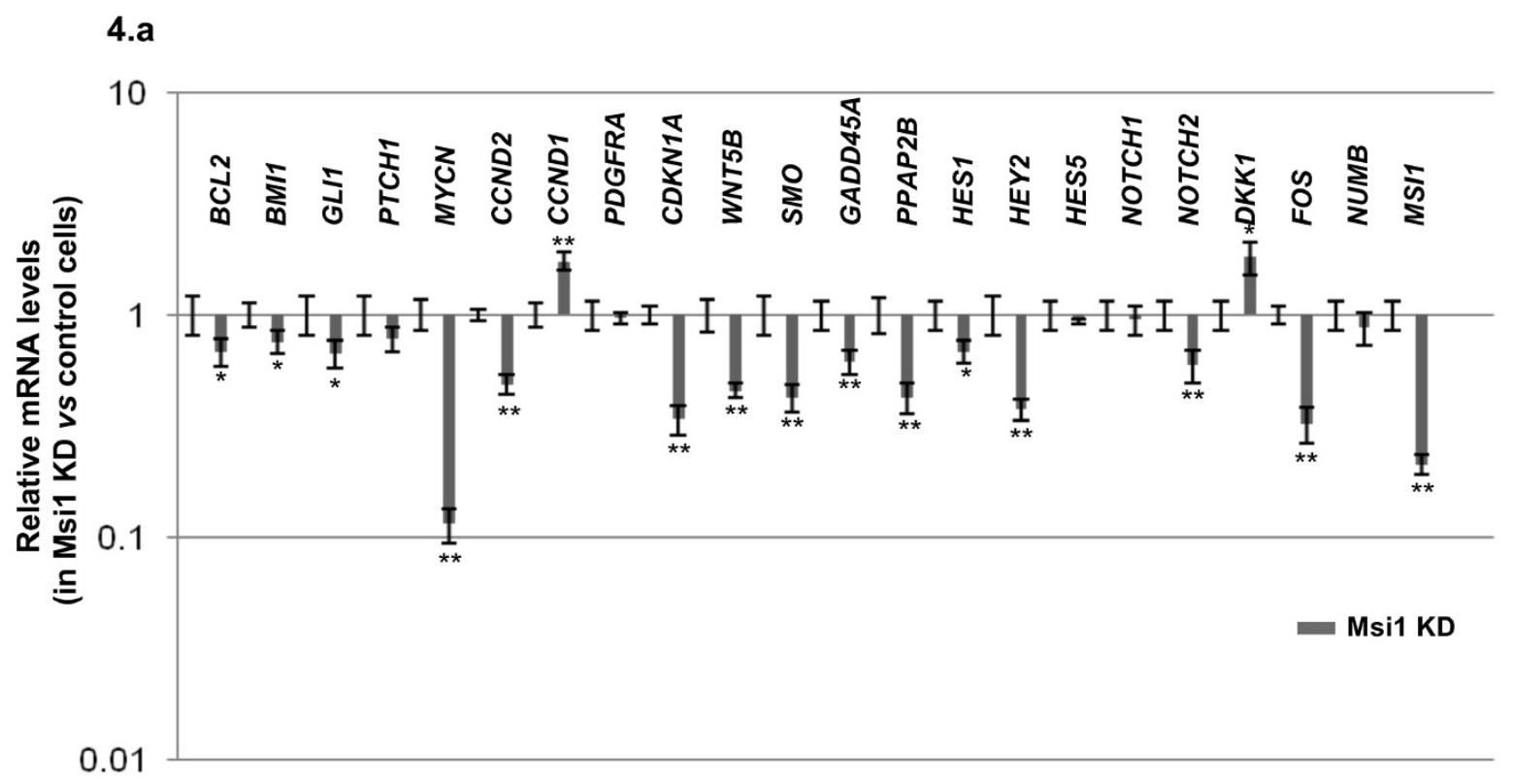

4.b

\begin{tabular}{|c|c|c|c|}
\hline GENE & Fold Change & GENE & Fold Change \\
\hline \multicolumn{4}{|l|}{ Hedgehog related } \\
\hline$B C L 2$ & $130 \%$ & Notch related & \\
\hline RMII & $155 \%$ & HESI & $\downarrow 30 \%$ \\
\hline A & $\downarrow 2570$ & HEY2 & $\downarrow 60 \%$ \\
\hline GLII & $\downarrow 50 \%$ & HES5 & $\approx$ \\
\hline PTCHI & $\downarrow 25 \%$ & ПLDJ & $\sim$ \\
\hline$M Y C N$ & $\downarrow 90 \%$ & NOTCHI & $\approx$ \\
\hline CCND2 & $\downarrow 50 \%$ & $\mathrm{NOTCH} 2$ & $\downarrow 40 \%$ \\
\hline$C C N D 1$ & $\uparrow>60 \%$ & Wnt related & \\
\hline HES1 & $\downarrow 30 \%$ & $C C N D 1$ & $\uparrow>60 \%$ \\
\hline PDGFRA & $\approx$ & $D K K 1$ & $\uparrow>70 \%$ \\
\hline$C D K N 1 A(\mathrm{p} 21)$ & $\downarrow>60 \%$ & FOS & $\downarrow 60 \%$ \\
\hline$P P A P 2 B$ & $\downarrow 50 \%$ & Other & \\
\hline WNT5B & $\downarrow 50 \%$ & $N U M B$ & $\approx$ \\
\hline$S M O$ & $\downarrow 50 \%$ & MSII & $\downarrow>70 \%$ \\
\hline GADD45A & $\downarrow 35 \%$ & & \\
\hline
\end{tabular}

\section{Figure 4}

Msil downstream effects. The RNA levels of a subset of Notch, Hedgehog and Wnt pathway components were quantified by quantitative RT-PCR in control and knockdown Daoy cells. Gene expression changes are represented (mean \pm se) using semi-logarithmic scale. The plot in the upper part (a) shows the fold change in mRNA levels for the Msil knockdown normalized to the housekeeping gene I5S. The table (b) summarizes the ratio (in percentage) of mRNA levels detected in Msil knockdown vs control. * represents $\mathrm{p}<0.05$ and $* * \mathrm{p}<0.01$. 
5.a
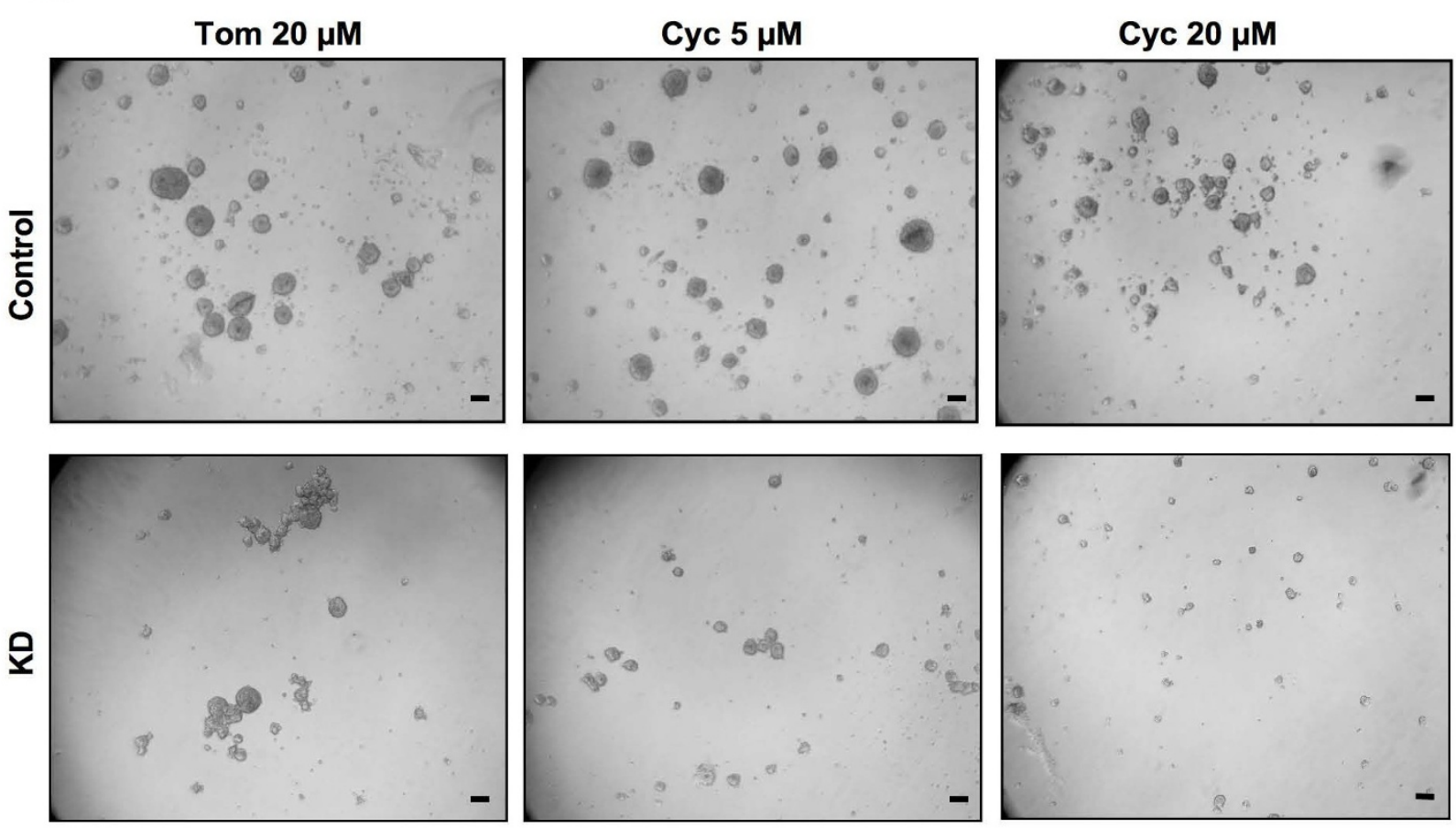

5.b

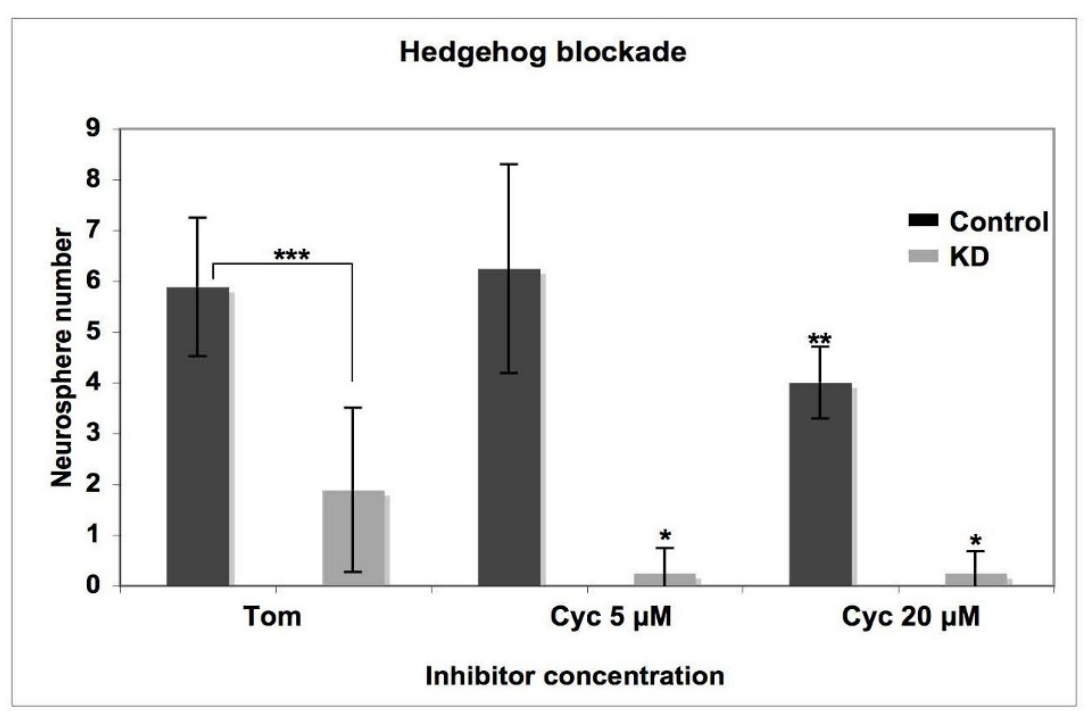

\section{Figure 5}

Effect of Hedgehog blockade upon neurosphere formation. The ability to form neuropheres in the presence of the Hedgehog inhibitor cyclopamine was evaluated in Daoy cells. Spheres derived from Daoy control (upper) and Msi l knockdown (KD; lower) were incubated for one week in the presence of inhibitor (Cyc) and tomatidine (Tom; negative control) at a concentration range of 5-20 $\mu \mathrm{M}$. A reduction in neurosphere size was observed in both cell lines; however, the knockdown cell line appeared to be more sensitive to cyclopamine treatment as the effects upon sphere formation were significant $(p<0.05)$ at lower concentrations of inhibitor. a) Representative images of the effects upon neurosphere formation at $5 \mu M$ and $20 \mu M$ cyclopamine are shown. Scale bars represent $100 \mu \mathrm{m}$. b) The average number of neurospheres per field is represented for control and KD cells after treatment with tomatidine and cyclopamine. * indicates $p<0.05, * * p<0.01$ and $* * * p<0.001$. 


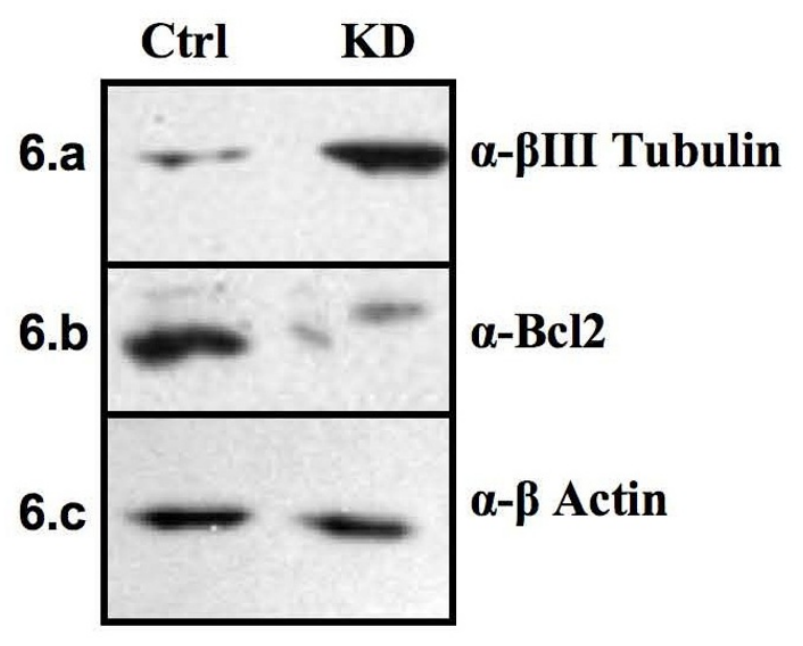

\section{Figure 6}

Cell differentiation and apoptosis. The levels of the neural marker $\beta$ III Tubulin and of the antiapoptotic protein $\mathrm{Bcl} 2$ were analyzed by western blot. The experiment was performed twice using two different cell extracts. a) The higher level of $\beta$ III Tubulin detected in knockdown (KD) vs control (Ctrl) indicates that Msil may play a role in inhibiting cell differentiation. In addition, the reduced levels of $\mathrm{Bcl} 2$ detected in the knockdown (b) suggested a potential role for Msil in preventing apoptosis. c) $\beta$-Actin was used as loading control.

differentiation. Decline in both $\mathrm{Bcl} 2$ protein (Figure 6) and BCL2 transcript (Figure 4) levels were also detected in the knockdown suggesting that Msi1 may block apoptosis in Daoy cells. As a more important reduction was detected at protein level than at mRNA level ( $30 \%$ down-regulation; Figure 4), additional post-trancriptional mechanisms might be mediating the decrease of $\mathrm{Bcl} 2$ protein in our model system. Overall, the results obtained in our model system are consistent with a recent report by Dobson et al. [25] which demonstrates that Msi1 has an inhibitory effect upon oligodendrocyte precursor differentiation and apoptosis.

\section{Discussion}

Msi1 is an RNA binding protein with an essential role in maintaining the stem cell state $[1,3,4]$. High levels of Msi1 have been found in several malignancies, including medulloblastoma $[5,6]$. As Msi1 expression was elevated in Daoy neurospheres (Figure 1), we asked if Msi1 may promote expansion of cancer cells. In this study, we used the cell line Daoy as our model system. Daoy is a wellcharacterized cell line, which among other features, expresses elevated levels of Msi1 [5], is able to form colonies in soft agar and neurospheres when cultured in the presence of growth factors, has functional Notch, Hedgehog and Wnt signaling pathways and is tumorigenic in nude mice [26-28]. We performed a shRNA mediated knockdown of Msi1 in Daoy and found that cancer cells expressing low levels of Msi1 were less clonogenic (proliferation assay), more differentiated (higher $\beta I I I$ Tubulin expression) and, possibly, more apoptotic (lower Bcl2 expression). We also observed a defect in neurosphere formation which was consistent with a potential role of Msi 1 in activating proliferation and/or preventing differentiation and apoptosis in Daoy cells. Taken together, our data suggest that Msi1 may contribute to the proliferation of cancer cells. This observation was in agreement with previous reports correlating high levels of Msi1 with glioma and astrocytoma malignancy $[8,9]$.

Notch, Hedgehog, Wnt and p53 are important pathways that are frequently found to be deregulated in cancer (reviewed in [14-17]). Msi1 represses translation of numb [12]; an antagonist of Notch and Hedgehog signaling pathways $[18,19]$ which also prevents degradation of the tumor suppressor p53 [20]. Msi1 also activates Wnt pathway through an autocrine mechanism [23]. Thus it is possible that high levels of Msi1 may deregulate Notch, Hedgehog, Wnt and p53 activities in cancer cells thereby contributing to tumor growth.

We performed gene expression analysis to determine the downstream effects derived from Msi1 depletion. Since Daoy is p53 defective, the effects detected in cell proliferation in our model system are therefore independent of p53. However, given that p53 inactivation is found in $50 \%$ of the malignancies (reviewed in [17]), an in-depth work to elucidate the possible effects of Msi1 upon p53 activity in cancer cells is highly desirable.

We demonstrated that Msi1 regulates the expression of several genes involved in cell proliferation and tumorigenicity such us MYCN, SMO, NOTCH2, CCND1, CCND2, CDKN1A, FOS, GLI1, and DKK1 [26,29-36]. Noteworthy was the differential expression of two cell cycle regulators: CDKN1A (encoding $\mathrm{p} 21^{\mathrm{WAF}}$ ) and CCND1 (encoding Cyclin D1). A 2-fold decrease was found in CDKN1A levels when Msi1 was depleted in Daoy, possibly due to a reduced Hedgehog activity. Battelli et al. [13] reported that over-expression of Msi1 in HEK293 activates cell proliferation by down-regulating p21 WAF protein levels. Using a knockdown model in Daoy, we showed that Msi1 increases p21 WAF transcription, possibly, via Hedgehog activation. Although found in different model systems, it seems that Msi1 may play a dual role in regulating $\mathrm{p} 21^{\mathrm{WAF}}$; positive and indirect at the level of transcription (as shown here) and negative and direct at the post-transcriptional level (as previously reported [13]). 
The up-regulation of CCND1 detected in the Msi1 knockdown was intriguing. CCND1 transcription is induced in response to many oncogenic signals like Ras, ErB2, Src and Wnt (reviewed in [37]) and CyclinD1 overexpression is associated with tumorigenesis and metastasis. Moreover, CCND1 expression is considered an early event in malignancy and its loss inhibits tumor formation in a Ptch $1^{+/}$mouse model [38]. On the other hand and in agreement with our observation, down-regulation of CCND1 has recently been reported by Rubio et al. during spontaneous mesenchymal cell transformation [39]. Therefore, the mechanism driving up-regulation of CCND1 and its biological implications in our knockdown model system would justify a more intense investigation.

Cross-talk within Notch, Hedgehog and Wnt pathways has often been reported [5,23,26,31,40-42] indicating that the activity of these pathways needs to be fine-tuned in order to maintain homeostasis. We observed that Msi1 regulated the expression of Hedgehog key components, including the pathway mediators SMO and GLI1 and the pathway downstream target $M Y C N$, known to control cell proliferation and tumorigenicity [29,30,34]. Interestingly, simultaneous expression of MSI1 and MYCN occurs in clinical specimens http://home.ccr.cancer.gov/oncology/ oncogenomics/, which posits MYCN as an attractive Msi1 downstream effector. Moreover, $M Y C N$ represses transcription of the tumor suppressor DKK1 [43]. We thus propose that down-regulation of $M Y C N$ in Daoy cancer cells after Msi1 depletion might induce expression of the Wnt repressor DKK1, therefore interconnecting Msi1, Wnt and Hedgehog signaling pathways. At least in part, this Msi1/MycN/Dkk-1 axis may explain the growth suppressive effect observed in our knockdown model system.

To determine the relevance of the Hedgehog pathway in Daoy cancer cells, we performed a neurosphere culture assay in the presence of cyclopamine. Cyclopamine inhibited neurosphere formation in both cases; however, the effects in the knockdown cells were evident at a significantly lower concentration of antagonist. This data was consistent with a partial down-regulation of Hedgehog activity after Msi1 depletion in Daoy cells. On the other hand, it does not exclude the possibility that Msi1 may also modulate the activity of additional cell proliferation pathways such as Notch or Wnt.

We also found that Msi1 increased NOTCH2 levels thus suggesting a potential role of Msi1 in contributing to tumor growth. NOTCH2 is a component of the Notch pathway that acts as a mitogen for cerebellar granule cell precursors [44] and whose expression has been associated with malignancy in brain tumors and with the persistence of cancer cells $[26,27,33]$. Indeed, it has been shown that
Notch blockade reduces cancer cells in Daoy and inhibits tumor engraftment in nude mice [26,27].

\section{Conclusion}

In summary, our data suggest that Msi1 modulates proliferation of cancer cells. Msi1 regulated expression of a set of genes with a well-established role in cell proliferation, cell differentiation and survival and its loss appeared to have a detrimental effect on the maintenance of cancer cells. We thus propose that, by hijacking normal cell signaling pathways, Msi1 may sustain cancer cells. Likely, Msi1 regulates additional genes and a systems biology approach needs to be carried out to identify new Msi1 direct targets (i.e. post-transcriptionally regulated genes) and uncover the gene network controlled by Msi1. We believe that the identification of additional Msi1 direct target genes is necessary to better understand the function of this RNA binding protein in cancer cells. These insights may provide a foundation for designing novel and more rational therapies.

\section{Competing interests}

The authors declare that they have no competing interests.

\section{Authors' contributions}

PCSD performed all the experiments, interpreted the results, contributed with scientific discussion and prepared the manuscript. TLB and SCB provided technical assistance. JYH and LOFP contributed with scientific discussion and manuscript preparation. All authors read and approved the final manuscript.

\section{Acknowledgements}

We thank Susan L. Naylor for the assistance with soft agar assays and Raymond L. Stallings for his comments about the manuscript. Msi1 polyclonal antibody was generated at the San Antonio Cancer Institute (SACI) Antigen \& Antibody core facility. This work was supported by the San Antonio Area Foundation (PGID 122760) and SACI and American Cancer Society (PGID 124139).

\section{Additional material}

\section{Additional file 1}

Table 1. qRT-PCR primers. The sequences of the primers utilized in this study are shown in the table.

Click here for file

[http://www.biomedcentral.com/content/supplementary/14712407-8-280-S1.pdf]

\section{Addendum}

During the review process of this manuscript, Sureban et al., [48] demonstrated Msil was necessary for tumor growth in a colon adenocarcinoma xenograft model. 


\section{References}

I. Kaneko Y, Sakakibara S, Imai T, Suzuki A, Nakamura Y, Sawamoto K Ogawa Y, Toyama Y, Miyata T, Okano H: Musashi I : an evolutionally conserved marker for CNS progenitor cells including neural stem cells. Dev Neurosci 2000, 22: I39-I53.

2. Sakakibara S, Okano H: Expression of neural RNA-binding proteins in the postnatal CNS: implications of their roles in neuronal and glial cell development. I Neurosci 1997, I 7:8300-83 I 2 .

3. Sakakibara S, Nakamura Y, Yoshida T, Shibata S, Koike M, Takano H, Ueda S, Uchiyama Y, Noda T, Okano H: RNA-binding protein Musashi family: roles for CNS stem cells and a subpopulation of ependymal cells revealed by targeted disruption and antisense ablation. Proc Natl Acad Sci USA 2002, 99:। 5 I94-I 5199.

4. Siddall NA, McLaughlin EA, Marriner NL, Hime GR: The RNA-binding protein Musashi is required intrinsically to maintain stem cell identity. Proc Natl Acad Sci USA 2006, 103:8402-8407.

5. Yokota N, Mainprize TG, Taylor MD, Kohata T, Loreto M, Ueda S, Dura W, Grajkowska W, Kuo JS, Rutka JT: Identification of differentially expressed and developmentally regulated genes in medulloblastoma using suppression subtraction hybridization. Oncogene 2004, 23:3444-3453.

6. Nakano A, Kanemura Y, Mori K, Kodama E, Yamamoto A, Sakamoto $\mathrm{H}$, Nakamura $Y$, Okano $\mathrm{H}$, Yamasaki M, Arita N: Expression of the Neural RNA-binding protein Musashil in pediatric brain tumors. Pediatr Neurosurg 2007, 43:279-284.

7. Toda M, lizuka $Y, Y u$ W, Imai T, Ikeda E, Yoshida K, Kawase T, Kawakami $Y$, Okano $H$, Uyemura $K$ : Expression of the neural RNA-binding protein Musashil in human gliomas. Glia 200I, 34:1-7.

8. Kanemura $Y$, Mori K, Sakakibara S, Fujikawa H, Hayashi H, Nakano A Matsumoto T, Tamura K, Imai T, Ohnishi T, et al.: Musashi I, an evolutionarily conserved neural RNA-binding protein, is a versatile marker of human glioma cells in determining their cellular origin, malignancy, and proliferative activity. Differentiation 200I, 68: |4|-|52.

9. Ma YH, Mentlein R, Knerlich F, Kruse ML, Mehdorn HM, Held-Feindt $\mathrm{J}$ : Expression of stem cell markers in human astrocytomas of different WHO grades. I Neurooncol 2008, 86:3। -45.

10. Seigel GM, Hackam AS, Ganguly A, Mandell LM, Gonzalez-Fernandez $\mathrm{F}$ : Human embryonic and neuronal stem cell markers in retinoblastoma. Mol Vis 2007, I 3:823-832.

II. Schulenburg A, Cech P, Herbacek I, Marian B, Wrba F, Valent P, Ulrich-Pur $H$ : CD44-positive colorectal adenoma cells express the potential stem cell markers musashi antigen (msil) and ephrin B2 receptor (EphB2). J Pathol 2007, 213:I52-I60.

12. Imai T, Tokunaga A, Yoshida T, Hashimoto M, Mikoshiba K, Weinmaster G, Nakafuku M, Okano H: The neural RNA-binding protein Musashil translationally regulates mammalian numb gene expression by interacting with its mRNA. Mol Cell Biol 200I, 2 I:3888-3900

13. Battelli C, Nikopoulos GN, Mitchell JG, Verdi JM: The RNA-binding protein Musashi-I regulates neural development through the translational repression of p2 IWAF-I. Mol Cell Neurosci 2006, 3 I :85-96.

14. Miele L: Notch signaling. Clin Cancer Res 2006, I 2: I074-I079.

15. Pasca di Magliano M, Hebrok M: Hedgehog signalling in cancer formation and maintenance. Nat Rev Cancer 2003, 3:903-911.

16. Evangelista $M$, Tian $H$, de Sauvage $F J$ : The hedgehog signaling pathway in cancer. Clin Cancer Res 2006, I 2:5924-5928.

17. Sigal A, Rotter V: Oncogenic mutations of the p53 tumor suppressor: the demons of the guardian of the genome. Cancer Res 2000, 60:6788-6793.

18. Guo M, Jan LY, Jan YN: Control of daughter cell fates during asymmetric division: interaction of Numb and Notch. Neuron 1996, | 7:27-41.

19. Di Marcotullio L, Ferretti E, Greco A, De Smaele E, Po A, Sico MA Alimandi M, Giannini G, Maroder M, Screpanti I, Gulino A: Numb is a suppressor of Hedgehog signalling and targets Gli for Itchdependent ubiquitination. Nat Cell Biol 2006, 8:|4I5-|423.

20. Colaluca IN, Tosoni D, Nuciforo P, Senic-Matuglia F, Galimberti V, Viale G, Pece S, Di Fiore PP: NUMB controls p53 tumour suppressor activity. Nature 2008, $45 \mathrm{I}: 76-80$.

21. Tse C, Xiang RH, Bracht T, Naylor SL: Human Semaphorin 3B (SEMA3B) located at chromosome $3 \mathrm{p} 2 \mathrm{I} .3$ suppresses tumor formation in an adenocarcinoma cell line. Cancer Res 2002, 62:542-546.
22. Eberhart CG: In search of the medulloblast: neural stem cells and embryonal brain tumors. Neurosurg Clin N Am 2007, I 8:59-69. viii-ix

23. Wang XY, Yin Y, Yuan H, Sakamaki T, Okano H, Glazer RI: Musashi I modulates mammary progenitor cell expansion through proliferin-mediated activation of the Wnt and Notch pathways. Mol Cell Biol 2008, 28:3589-99.

24. Chen JK, Taipale J, Cooper MK, Beachy PA: Inhibition of Hedgehog signaling by direct binding of cyclopamine to Smoothened. Genes Dev 2002, 1 6:2743-2748.

25. Dobson NR, Zhou YX, Flint NC, Armstrong RC: Musashil RNAbinding protein regulates oligodendrocyte lineage cell differentiation and survival. Glia 2008, 56:3 I8-330.

26. Fan X, Mikolaenko I, Elhassan I, Ni X, Wang Y, Ball D, Brat DJ, Perry A, Eberhart CG: Notch I and notch2 have opposite effects on embryonal brain tumor growth. Cancer Res 2004, 64:7787-7793.

27. Fan X, Matsui W, Khaki L, Stearns D, Chun J, Li YM, Eberhart CG: Notch pathway inhibition depletes stem-like cells and blocks engraftment in embryonal brain tumors. Cancer Res 2006, 66:7445-7452.

28. Li Y, Guessous F, Johnson EB, Eberhart CG, Li XN, Shu Q, Fan S, Lal $B$, Laterra J, Schiff D, Abounader R: Functional and molecular interactions between the HGF/c-Met pathway and c-Myc in large-cell medulloblastoma. Lab Invest 2008, 88:98-I I I.

29. Hatton BA, Knoepfler PS, Kenney AM, Rowitch DH, de Alboran IM, Olson JM, Eisenman RN: $\mathbf{N}$-myc is an essential downstream effector of Shh signaling during both normal and neoplastic cerebellar growth. Cancer Res 2006, 66:8655-866I.

30. Oliver TG, Grasfeder LL, Carroll AL, Kaiser C, Gillingham CL, Lin SM, Wickramasinghe R, Scott MP, Wechsler-Reya RJ: Transcriptional profiling of the Sonic hedgehog response: a critical role for $\mathbf{N}$-myc in proliferation of neuronal precursors. Proc Natl Acad Sci USA 2003, 100:7331-7336.

31. Hallahan AR, Pritchard JI, Hansen S, Benson M, Stoeck J, Hatton BA Russell TL, Ellenbogen RG, Bernstein ID, Beachy PA, Olson JM: The SmoAl mouse model reveals that notch signaling is critical for the growth and survival of sonic hedgehog-induced medulloblastomas. Cancer Res 2004, 64:7794-7800.

32. Roninson IB: Oncogenic functions of tumour suppressor p2I(Wafl/Cipl/Sdil): association with cell senescence and tumour-promoting activities of stromal fibroblasts. Cancer Lett 2002, 179:1-14.

33. Boulay JL, Miserez AR, Zweifel C, Sivasankaran B, Kana V, Ghaffari A, Luyken C, Sabel M, Zerrouqi A, Wasner M, et al.: Loss of NOTCH2 positively predicts survival in subgroups of human glial brain tumors. PLOS ONE 2007, 2:e576.

34. Clement V, Sanchez P, de Tribolet N, Radovanovic I, Ruiz i Altaba A: HEDGEHOG-GLII signaling regulates human glioma growth, cancer stem cell self-renewal, and tumorigenicity. Curr Biol 2007, I 7: 165-172.

35. Cowling VH, D'Cruz CM, Chodosh LA, Cole MD: c-Myc transforms human mammary epithelial cells through repression of the Wnt inhibitors DKKI and SFRPI. Mol Cell Biol 2007 27:5|35-5|46.

36. Vibhakar R, Foltz G, Yoon JG, Field L, Lee H, Ryu GY, Pierson J, Davidson $B$, Madan A: Dickkopf-I is an epigenetically silenced candidate tumor suppressor gene in medulloblastoma. Neuro Oncol 2007, 9: I35-144

37. Fu M, Wang C, Li Z, Sakamaki T, Pestell RG: Minireview: Cyclin DI: normal and abnormal functions. Endocrinology 2004, | 45:5439-5447.

38. Pogoriler J, Millen K, Utset M, Du W: Loss of cyclin DI impairs cerebellar development and suppresses medulloblastoma formation. Development 2006, I33:3929-3937.

39. Rubio D, Garcia S, Paz MF, De la Cueva T, Lopez-Fernandez LA, Lloyd AC, Garcia-Castro J, Bernad A: Molecular characterization of spontaneous mesenchymal stem cell transformation. PLoS ONE 2008, 3:el 398.

40. van Es JH, van Gijn ME, Riccio O, Born M van den, Vooijs M, Begthel H, Cozijnsen M, Robine S, Winton DJ, Radtke F, Clevers H: Notch/ gamma-secretase inhibition turns proliferative cells in intestinal crypts and adenomas into goblet cells. Nature 2005, 435:959-963.

4I. Duncan AW, Rattis FM, DiMascio LN, Congdon KL, Pazianos G, Zhao C, Yoon K, Cook JM, Willert K, Gaiano N, Reya T: Integration of 
Notch and Wnt signaling in hematopoietic stem cell maintenance. Nat Immunol 2005, 6:3 I4-322.

42. Sengupta A, Banerjee D, Chandra S, Banerji SK, Ghosh R, Roy R, Banerjee S: Deregulation and cross talk among Sonic hedgehog, Wnt, Hox and Notch signaling in chronic myeloid leukemia progression. Leukemia 2007, 21:949-955.

43. Koppen A, Ait-Aissa R, Hopman S, Koster J, Haneveld F, Versteeg R, Valentijn LJ: Dickkopf- $I$ is down-regulated by MYCN and inhibits neuroblastoma cell proliferation. Cancer Lett 2007, 256:2/8-228.

44. Solecki DJ, Liu XL, Tomoda T, Fang Y, Hatten ME: Activated Notch2 signaling inhibits differentiation of cerebellar granule neuron precursors by maintaining proliferation. Neuron 200I, 3 I:557-568.

45. Penalva LO, Keene JD: Biotinylated tags for recovery and characterization of ribonucleoprotein complexes. Biotechniques 2004, 37:608-610.

46. Taylor MD, Poppleton H, Fuller C, Su X, Liu Y, Jensen P, Magdaleno S, Dalton J, Calabrese C, Board J, et al.: Radial glia cells are candidate stem cells of ependymoma. Cancer Cell 2005, 8:323-335.

47. Rozen S, Skaletsky H: Primer 3 on the WWW for general users and for biologist programmers. Methods Mol Biol 2000, 132:365-386.

48. Sureban Sripathi M, May Randal, George Robert J, Dieckgraefe Brian K, McLeod Howard L, Ramalingam Satish, Bishnupuri Kumar S, Natarajan Gopalan, Anant Shrikant, Houchen Courtney W: Knockdown of RNA Binding Protein Musashi-I Leads to Tumor Regression In Vivo. Gastroenterology 2008, I34:| 448-1458.

\section{Pre-publication history}

The pre-publication history for this paper can be accessed here:

http://www.biomedcentral.com/1471-2407/8/280/pre pub

Publish with Bio Med Central and every scientist can read your work free of charge

"BioMed Central will be the most significant development for disseminating the results of biomedical research in our lifetime. "

Sir Paul Nurse, Cancer Research UK

Your research papers will be:

- available free of charge to the entire biomedical community

- peer reviewed and published immediately upon acceptance

- cited in PubMed and archived on PubMed Central

- yours - you keep the copyright

Submit your manuscript here:

http://www.biomedcentral.com/info/publishing_adv.asp
BioMedcentral 